\title{
Anmerkungen für den Übungsteil
}

Der Autor empfiehlt, vor dem Anschauen der Lösung jeweils einen ehrlichen Versuch zur eigenständigen Beantwortung der Frage zu machen und die Antwort möglichst zu begründen.

$\mathrm{Zu}$ jeder Frage gehört jeweils nur eine richtige Lösung. Es ist also jeweils nur ein Buchstabe anzukreuzen.

Für die Beantwortung des Fragentyps „Kausale Verknüpfung“ wird folgendes Lösungsschema benötigt:

\begin{tabular}{llll}
\hline Aussage 1 & Aussage 2 & Verknüpfung & Lösungsbuchstabe \\
\hline richtig & richtig & richtig & (A) \\
richtig & richtig & falsch & (B) \\
richtig & falsch & - & (C) \\
falsch & richtig & - & (D) \\
falsch & falsch & - & (E) \\
\hline
\end{tabular}

